\title{
A Tracer Study in a Vertical Flow Constructed Wetland Treating Septage
}

\author{
Jason Jie Xiang Bui ${ }^{1}$, Yee Yong Tan ${ }^{1}$, Tang Fu Ee ${ }^{1, *}$ and Carrie Ho Lee Ing ${ }^{1}$ \\ 1 Department of Civil and Construction Engineering, Curtin University, Malaysia. CDT 250 98009, Miri, \\ Sarawak, Malaysia; jason.bui@postgrad.curtin.edu.my (J.B.); tan.yee.yong@curtin.edu.my (Y.Y.); \\ carrie.ho@curtin.edu.my (C.H.) \\ * Correspondence: tang.fu.ee@curtin.edu.my; Tel.: +6085 443939 \\ Academic Editor: name \\ Received: date; Accepted: date; Published: date
}

\begin{abstract}
Purpose - This study aims to investigate the hydraulic behaviour of a pilot-scale, two-staged, vertical flow constructed wetland (VFCW) for septage treatment, in terms of factors such as hydraulic retention time and hydraulic loading rate, and its influence on the treatment dynamics. Due to intermittent feeding mode of VFCW systems and variation in its loading, its hydraulic behaviour is highly variable, and need to be understood to optimize its treatment performance.

Design/methodology/approach - Tracer test were carried out using bromide ion with varying hydraulic loading rates (HLR) of $6.82 \mathrm{~cm} / \mathrm{d}, 9.09 \mathrm{~cm} / \mathrm{d}$ and $11.40 \mathrm{~cm} / \mathrm{d}$ (i.e. equivalent to $75 \mathrm{~L} / \mathrm{d}$, $100 \mathrm{~L} / \mathrm{d}$, and $125 \mathrm{~L} / \mathrm{d}$ respectively). Tracer data is then analysed using the Residence Time Distribution (RTD) method.

Findings - RTD analysis showed that the increase in HLR increases the average hydraulic retention time (HRT). Subsequently, the increase in HLR results in a lower recovery of effluent, resulting in poor productivity in treatment. The study also showed that the removal of nitrogen and organic matter improved with increasing HRT. However, observations shows no correlation between HRT and total solids removal.

Originality/value - A performance evaluation method (by tracer) is proposed to understand the hydraulics and dynamics of treatment in VFCWs treating septage.
\end{abstract}

Keywords hydraulic retention time; tracer test; hydraulic loading rate; vertical flow constructed wetland; residence time distribution, septage treatment

Paper type Research paper

\section{Introduction}

Domestic wastewater in Malaysia is mostly segregated into greywater and blackwater. Blackwater is mostly treated in individual septic tanks (ISTs) (Bradley and Dhanagunan, 2004). ISTs effectively prevent the direct discharge of sewage by providing primary treatment. However, to operate ISTs at optimum, the accumulated sludge in the tanks needs to be removed periodically. This is because the sludge contains high concentrations of solids, organic matter, and nutrient. Construction of conventional treatment plants to manage the significant amounts of generated sludge is possible, but tend to be expensive and impractical for smaller towns and cities. Hence, a sustainable solution such as the vertical flow constructed wetland (VFCW) is proposed for management of septage.

Constructed wetlands have been used in the treatment of a variety of wastewater including agricultural wastewater (Tanner et al., 1995), industrial wastewater (Vrhovšek et al., 1996), and septage (T Koottatep et al., 2001; Paing and Voisin, 2005; Jong and Tang, 2016). Septage treatment using VFCW systems is complex due to the contaminants in septage being at least $10-100$ times 
stronger (Cofie et al., 2006) than domestic wastewater. Unlike other typical VFCW systems treating wastewaters (Kadlec and Wallace, 2008), the filters on VFCW systems treating septage do not incorporate a sand filter layer at the top. Instead, the substrate consists of larger particles sizes compared to typical VFCW systems (treating wastewater or stormwater) to prevent clogging issues, due to high concentrations of solids from septage (Jong and Tang, 2016).

The hydraulic behaviour of the VFCW, which is subject to factors such as its hydraulic retention time (HRT) and water distribution within its substrate, is important towards understanding its treatment processes and optimizing its efficiency. The study of hydraulic behaviour includes the study of the influence of the hydraulic loading rate (HLR) on treatment efficiency, and HRT of the system (Ghosh and Gopal, 2010), whereas the treatment performance of the system relies on its ability to maintain its hydraulics (i.e. liquid motion) over its life span. The pollutant removal mechanism is an integrated system in which physical, chemical, and biological processes are involved. In VFCWs, removal of solids mostly occur through filtration on the surface of the substrate (Vymazal et al., 1998; Kadlec and Wallace, 2008). Furthermore, microbial degradation within the substrate media removes organic matter, whereby the removal efficiency increases with extended hydraulic retention time (HRT) (Sirianuntapiboon et al., 2006). Similarly, the removal of nitrogen increases with increasing HRT resulting in a more complete nitrification process. HLR may be utilized instead of solid loading rate (SLR) due to a high level of variation in solids content (Koottatep et al., 2005). This is because controlling SLR would require monitoring and measurement of total solids (TS) content before each loadings, whereas HLR requires measurement of volume, which is easily obtainable on site.

Usually, the VFCW system is fed intermittently with alternating feedings allowing drainage and full emptying of the system, which makes its hydraulic behaviour highly dynamic. During the acclimatization stage, a sludge deposit layer is formed over the top layer of the system due to the accumulation of organic matter and solids through physical filtration as the influent infiltrates through the substrate medium of the system (Lana et al., 2013; Molle, 2014). According to Molle (2014), the sludge deposit layer enhances filtration and water distribution on the system's surface, by reducing the wetland's effective porosity and permeability. However, the intermittent feeding regime increases the system's oxygenation efficiency, which improves microbial degradation of organic matter accumulated at the top layer of the filter, avoiding clogging (Molle et al., 2006). Also, increased degradation and dewatering of the sludge deposit layer between feedings results in formations of cracks (Jong and Tang, 2016), which would reduce the overall HRT caused by preferential flows. Ultimately, the reduced contact time would deteriorate effluent quality. Furthermore, dead zones may also form throughout the operation resulting in reduced HRT and treatment efficiency of the system (Cota et al., 2011). Nevertheless, shorter resting periods between loadings coupled with high hydraulic loads reduces the probability of cracks formation as dewatering and mineralisation of the sludge deposit layer is reduced. This is because it decreases re-oxygenation in the system, which reduces aerobic biodegradation of the sludge deposit layer (Molle et al., 2006; Jong and Tang, 2016). As a result, HRT increases and the treatment efficiency of the system is enhanced. Therefore, the understanding of the hydraulic behaviour and the effects of different operational parameters on HRT is crucial in optimizing treatment.

Tracer testing can be conducted as a means to understand the hydraulic behaviour of water in the VFCW system (Kadlec and Wallace, 2008). Testing involves tracing the progress of solute transport through the wetland system by addition of substances such as salt ions, fluorescent dyes or titrated water. From the test, the actual residence time distribution (RTD) in the system can be obtained. The RTD curve is the probability density function for residence time of water in the wetland (Kadlec and Wallace, 2008). In simple terms, the curve represents the time that various portions of the fluid spend in the system. Additionally, the overall HRT of the system can be obtained from the RTD analysis.

In many studies, the efficiency of VFCW system is evaluated based on an influent-effluent monitoring procedure, where the overall treatment performance is determined according to the difference between influent and effluent quality (Paing and Voisin, 2005; Sirianuntapiboon et al., 2006; Lana et al., 2013). Hence, the design of such systems still remain at a "black-box" level, in which 
"rules-of-thumb" are still used as design criteria. Moreover, the overall removal efficiency is commonly used to determine the capacity and operational strategies of the wetland beds (Kumar and Zhao, 2011).

Therefore, this paper presents a study of the hydraulic behaviour of a pilot-scale VFCW, which was aimed at determining the correlation between treatment dynamics and hydraulic behaviour in a treatment cycle. In particular, the retention time analysis (RTD) is carried out by performing a tracer test to determine the influence of HLR on the hydraulic behaviour of the VFCW.

\section{Materials and Methods}

\subsection{Experimental Setup}

The experimental setup of the VFCW system is shown in Figure 1 below. Each VFCW cell consist of similar substrate configurations in which only two cells were planted with phragmites karka. Planted cells were expected to have high treatment efficiency. From literature, macrophytes play a vital role in enhancing treatment performance by providing surfaces and oxygen for microorganism growth in the rhizophere for better nitrification. In addition, they release carbon from photosynthesis, which optimizes denitrification and organic matter removal (Langergraber, 2005; Saeed and Sun, 2012). Hence, this paper presents results from planted cells.

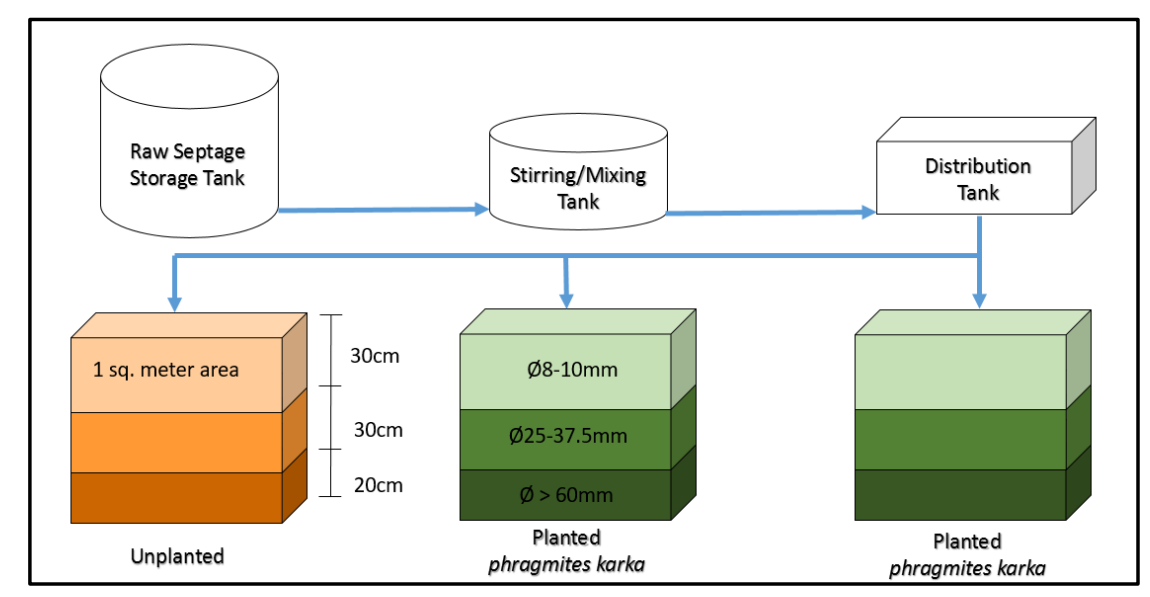

Figure 1 The design configuration of the first stage of the VFCW located in the university, which is the main focus in this study. Raw septage was obtained from residential sources and delivered to the raw septage storage tank. From the storage tank, septage is transferred to a stirring/mixing tank to be mixed homogeneously before transferring to a distribution tank and distributed to the individual VFCW beds via peripheral pumps.

Each cell consist of a $20 \mathrm{~cm}$ drainage layer built using large gravels $(\varnothing>6.00 \mathrm{~cm})$ at the bottom of the bed. The main layers consist of two different sized crushed gravels $(\varnothing 2.5-3.75 \mathrm{~cm}$ and $\emptyset 0.80$ $-1.00 \mathrm{~cm}$ ), with the smaller-sized gravels stacked on top of the larger-sized gravels, each with a depth of $30 \mathrm{~cm}$. The cells have a surface area of $1.1 \mathrm{~m}^{2}$. Two vertical ventilation pipes were installed along the wetland beds to enhance reaeration. The septage used in this study was collected and delivered from residential sources by a local environmental servicer. The septage was filtered to remove any gross solids such as plastic material, clothing, hair, and others, to prevent clogging in the pipes without altering its original characteristics.

\subsection{Experimental Tracer}

The tracer test was carried out using sodium bromide $(\mathrm{NaBr})$, due to its biological stability and conservative nature (Kadlec and Wallace, 2008). The tracer was injected into the septage and the mixture was homogenised before loading, similar to that of a step input injection, resulting in constant tracer concentrations in the influent (Fogler and Brown, 1986). 
Intermittent feeds was utilized to ensure sufficient oxygen level in the wetland bed for enhanced nitrogen and organic matter removal. Variations in the HLR was achieved by controlling the volume of septage added. Low, medium, and high HLR (i.e. $6.82 \mathrm{~cm} / \mathrm{d}, 9.09 \mathrm{~cm} / \mathrm{d}$, and $11.4 \mathrm{~cm} / \mathrm{d}$, equivalent to $75 \mathrm{~L} / \mathrm{d}, 100 \mathrm{~L} / \mathrm{d}$, and $125 \mathrm{~L} / \mathrm{d}$ respectively) cases were studied. Due to high amounts of organic content and solids in the septage, a resting period between loadings was required to prevent clogging of the system.

Hua et al. (2014) states that for a resting period of 3, 6, and 10 days, the hydraulic conductivity and effective porosity of the substrate media would improve significantly. However, for a resting period of 10 days, a significant increase in effective porosity could occur, which would lead to shortcircuiting. Hence, the feeding regime incorporates a 6-day resting period between loadings. 3 days resting is expected to be insufficient as the system would need longer time to recover due to the high solids and organics content in septage. Table 1 below presents the HLRs used for this study. A total of 12 experimental runs were conducted, with 4 runs conducted for each HLR case.

Table 1 Feeding regime throughout operation of VFCW.

\begin{tabular}{lll}
\hline HLR (L/d) & HLR $(\mathbf{c m} / \mathbf{d})$ & Resting Period (days) \\
\hline 75 & 6.82 & 6 \\
100 & 9.09 & 6 \\
125 & 11.04 & 6 \\
\hline
\end{tabular}

\subsection{Sampling and Testing}

The effluent flow rate was determined by measuring the volume collected at various time intervals during each loading. A total of $200 \mathrm{~mL}$ of effluent was sampled for each time interval to carry out the quality test. The concentrations of ammonium $\left(\mathrm{NH}_{4}^{+}-\mathrm{N}\right)$, nitrate $\left(\mathrm{NO}_{3}{ }^{-}-\mathrm{N}\right)$, dissolved oxygen (DO), $\mathrm{pH}$, and temperature were measured on site using an HQ40d portable multi-parameter meter with specific probes. The laboratory analysis includes the measurements of Total Nitrogen (TN) and Chemical Oxygen Demand (COD) using HACH DR2800 - spectrophotometer. The concentration of total solids (TS) was determined using the oven drying method. The concentration of bromide was measured using Hach ${ }^{\circledR}$ MM340 radiometer with bromide ion selective electrode.

Determination of the removal efficiencies is in accordance to (Liu et al., 2013) by comparing the volume and concentration of the influent to the volume and quality of the effluent. However, a conservative approach is conducted whereby the total volume of effluent replaces the volume of influent. The removal efficiency equation is given as:

$$
\mathrm{E}=\frac{\mathrm{C}_{\mathrm{i}} \sum_{\mathrm{i}=1}^{\mathrm{N}} \mathrm{V}_{\mathrm{e}}-\sum_{\mathrm{i}=1}^{\mathrm{N}} \mathrm{C}_{\mathrm{e}} \mathrm{V}_{\mathrm{e}}}{\mathrm{C}_{\mathrm{i}} \sum_{\mathrm{i}=1}^{\mathrm{N}} \mathrm{V}_{\mathrm{e}}} \times 100 \%,
$$

such that, $\mathrm{C}_{\mathrm{i}}$ and $\mathrm{C}_{\mathrm{e}}$ are the influent and effluent concentrations [ML-3] respectively, and $\mathrm{V}_{\mathrm{i}}$ and $\mathrm{V}_{\mathrm{e}}$ are

161 the volume of influent and effluent $\left[\mathrm{L}^{3}\right]$ respectively.

\subsection{Tracer Data Analysis}

This study utilized the method proposed by (Fogler and Brown, 1986) to analyse the tracer data for step inputs. The variables determined from this method includes the average retention time, variance, and tracer mass recovered to describe the effect of HLR on hydraulic behaviour of the wetland system. Equations (2) to (4) below are equations for pulse input RTD analysis:

$$
\begin{gathered}
E(t)=\frac{C(t)}{\int_{0}^{\infty} \mathrm{C}(\mathrm{t}) d \mathrm{t}^{\prime}} \\
\tau=\int_{0}^{\infty} \mathrm{tE}(\mathrm{t}) \mathrm{dt}
\end{gathered}
$$




$$
\sigma^{2}=\int_{0}^{\infty} t^{2} E(t) d t-\tau^{2}
$$

167

168

169

170

171

172

173

174

175

such that, $\mathrm{E}(\mathrm{t})$ is the residence time distribution function $\left[\mathrm{T}^{-1}\right], \mathrm{C}(\mathrm{t})$ is the concentration of tracer at time, $\mathrm{t}\left[\mathrm{ML}^{-3}\right], \tau$ is the average residence time $[\mathrm{T}], \sigma^{2}$ is the variance $\left[\mathrm{T}^{2}\right]$ and $\sigma$ is the standard deviation [T]. Equation (5) below relates the information to suit step input conditions:

$$
E(t)=\frac{d}{d t}\left[\frac{C(t)}{C_{0}}\right]_{\text {step }}
$$

such that, $\mathrm{C}_{0}$ is the concentration of tracer in the feed $\left[\mathrm{ML}^{-3}\right]$. Since flow is unsaturated in the VFCW system, the varying flow rate patterns could significantly affect the tracer response curve (Headley and Kadlec, 2007). Thus, to suit the unsaturated flow conditions, modifications to Equation (5) was required. To easily compare and analyse tracer data from unsaturated flow, the tracer mass was used instead of tracer concentrations (Headley and Kadlec, 2007). The new expression is given as:

$$
E(t)=\frac{d}{d t}\left[\frac{m(t)}{M_{0}}\right]_{\text {step }}
$$

such that, $\mathrm{m}(\mathrm{t})$ is the tracer mass at time $\mathrm{t}[\mathrm{M}]$, and $\mathrm{M}_{0}$ is the total recovered tracer mass $[\mathrm{M}]$.

\section{Results and Discussion}

\subsection{Effect of Hydraulic Loading Rate (HLR) on Flow Pattern, Maximum Flow Rate, and Water Recovery}

The flow characteristics of the system with respect to variation in HLRs are presented here. Due to space limitations, only one case was chosen and presented here. Furthermore, HLRs of $75 \mathrm{~L} / \mathrm{d}, 100$ $\mathrm{L} / \mathrm{d}$, and $125 \mathrm{~L} / \mathrm{d}$ were examined to study the effects of low, moderate, and high HLR cases respectively. Figure 2 below shows the typical effluent flow profile, which comprises of three stages for all HLR cases. Also, a summary of the analysis are shown in Table 2.

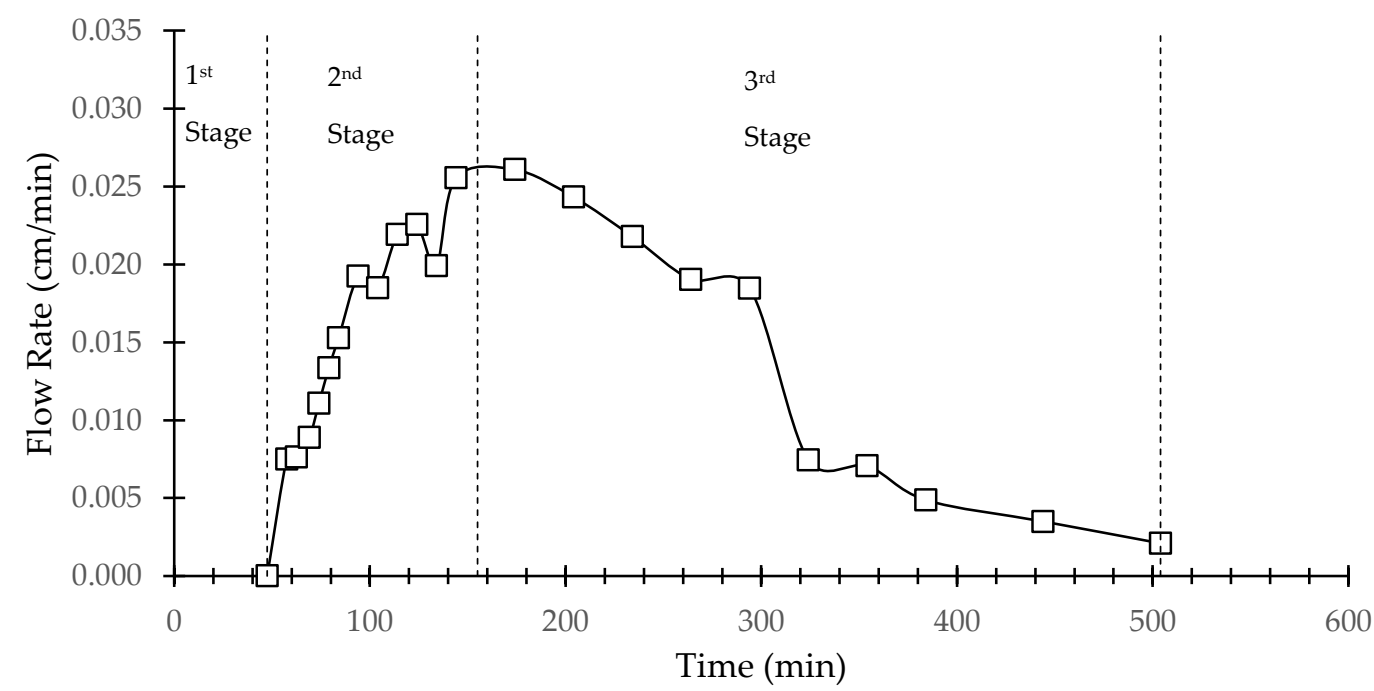

Figure 2 Typical effluent flow profile due to varying HLR cases, which consist of three (3) stages in flow. The first stage is described by the delay in flow, followed by a transition to the second stage in which a significant amount of flow was observed that increases to a maximum. The third stage is observed as a steady decrease in flow after reaching a maximum flow.

Table 2 Maximum effluent flow rate due to varying HLR and solids content.

\begin{tabular}{llllll}
\hline $\begin{array}{l}\text { HLR } \\
(\mathrm{L} / \mathrm{d})\end{array}$ & $\begin{array}{l}\text { HLR } \\
(\mathrm{cm} / \mathrm{d})\end{array}$ & $\begin{array}{l}\text { Average Sludge } \\
\text { Thickness throughout } \\
\text { operation }(\mathrm{cm})\end{array}$ & $\begin{array}{l}\text { Total Solids } \\
\text { Concentration } \\
(\mathrm{g} / \mathrm{L})\end{array}$ & $\begin{array}{l}\text { Solids } \\
\text { Content }(\mathrm{g})\end{array}$ & $\begin{array}{l}\text { Maximum Flow } \\
\text { Rate }(\mathrm{cm} / \mathrm{min})\end{array}$ \\
\hline
\end{tabular}




\begin{tabular}{llllll}
\hline 75 & 6.82 & $5.00-6.00$ & $2.00-5.00$ & $150-375$ & $0.015-0.065$ \\
100 & 9.09 & $4.00-7.00$ & $8.00-12.80$ & $800-1280$ & $0.020-0.042$ \\
125 & 11.04 & $6.00-9.00$ & $4.00-7.50$ & $500-940$ & $0.004-0.007$ \\
\hline
\end{tabular}

The first stage is determined as the period before effluent flow initiates. This delay may be attributed to the time required for the influent to infiltrate the sludge deposit layer on the wetland surface due to the low permeability of the layer before being discharged (Molle, 2014). It is during this stage that significant water ponding was observed with negligible change in water depth. For low, moderate, and high HLR cases, the duration of the first stage on average were 37 minutes, 59 minutes, and 29 minutes respectively. Comparison between low and moderate HLR cases shows that the slower infiltration rate for moderate HLR cases is likely to be due to the difference in the solids content of the septage, in which the highest solids content for the low and moderate HLR cases were determined to be $375 \mathrm{gm}$ and $1280 \mathrm{gm}$ respectively. As a result, the effective porosity and permeability reduces, resulting in a slower infiltration rate (Jong and Tang, 2016). On the contrary, high HLR cases indicated the highest infiltration rate compared to the low and moderate HLR cases. The increased infiltration rate may be driven by the significant hydraulic head difference (Molle et al., 2006), although, solids content is generally high (as compared to the low HLR case), in addition to having the greatest overall sludge deposit layer thickness throughout the operation. The first stage in the effluent flow profile ends when a significant amount of effluent flow was observed, thus, transitioning to the second stage of flow.

The transition into the second stage in the effluent flow profile occurs when a significant flow rate was observed. It is during this stage that a rapid increase in flow rate was observed before reaching a maximum outflow. Also, a significant change in water depth was observed compared to that of the first stage in the flow profile. For low, moderate, and high HLR cases, the peak outflow ranges from $0.015-0.065 \mathrm{~cm} / \mathrm{min}, 0.020-0.042 \mathrm{~cm} / \mathrm{min}$, and $0.004-0.007 \mathrm{~cm} / \mathrm{min}$ respectively. On average, it was observed that low HLR cases have the highest flow velocity. Higher solids content as well as a thicker sludge deposit layer may cause the slower flow velocity for moderate and high HLR cases. The reduction in maximum flow rate indicated that the wetland is more susceptible to clogging with a higher solids content, which was a result of increasing the HLR intensity (Molle, 2014). In addition, the accumulation of the sludge deposit layer would increase the clogging tendencies in the substrate medium, resulting in a reduced flow velocity (Langergraber et al., 2003; Rajabzadeh et al., 2015). Moreover, the thicker sludge deposit layer would retain more water in the system, as well as increase the capillary action, which would reduce the flow rate of water (Cota et al., 2011). In contrast with the first stage of flow, in terms of controlling flow rate, the significance of solids content and sludge thickness is more apparent than the hydraulic head difference for high HLR cases. Nevertheless, the effect of hydraulic head difference reduces with decreasing water depth over time.

The third and final stage in the flow profile occurs when flow steadily decreases after reaching a maximum outflow. This continues until no significant flow was visually observed. The steady decrease of flow could be related to the decrease in hydraulic head over time, resulting in reduced flow rate (Molle et al., 2006).

Furthermore, the results also indicated that the water recovery varied significantly for all HLR cases. The average recovery for low HLR cases was approximately $76 \%$, amounting to $57.1 \mathrm{~L}$ of effluent. The percentage recovery for low HLR was the highest, followed by moderate, and high HLR with $53 \%$ and $9 \%$ recovery (amounting to $53.0 \mathrm{~L}$ and $11.2 \mathrm{~L}$ ) respectively. The low water recovery may be due to the increase in sludge deposit and solids content. The higher solids content would result in the system's tendency to clog due to reduction in effective porosity, hence, retaining more water in the system (Langergraber et al., 2003). Nonetheless, higher hydraulic and organic loads would decrease biosolids mineralisation of the sludge deposit layer, impeding the flow of water through the system (Jong and Tang, 2016).

\subsection{Treatment Performance}

Table 3 below shows the overall treatment performance of the system throughout the study. Firstly, the average removal of COD increases with increasing HLR intensity. This may be due to 
enhanced filtration of particulate organic matter from the sludge deposit layer. The increasing solids content with increased HLR intensity reduces the effective porosity of the sludge deposit layer, resulting in enhanced filtration action (Molle, 2014). The increase in sludge deposit layer thickness and solids content from increasing HLR intensity would result in reduced flow rate (Langergraber et al., 2003; Rajabzadeh et al., 2015) resulting in increased HRT. The increase in HRT would enhance aerobic degradation of organic matter. Aerobic degradation is more likely to occur due to the high oxygen transfer of the VFCW system (Saeed and Sun, 2012). Similarly, total solids (TS) removal was observed to increase with increasing HLR intensity. This would suggest enhanced filtration of solids from the sludge deposit layer. The increase in solids content and thickness of the sludge deposit layer would reduce its effective porosity, hence improving the filtration of solids. However, it should be noted that removal of TS is highly dynamic with average removal percentages ranging from $42.9 \%$ $87.5 \%, 78.1 \%-91.3 \%$, and $71.4 \%-97.9 \%$ for low, moderate, and high HLR cases respectively. Large fluctuations in TS removal would indicate that some of the filtered solids were flushed out of the system due to size reduction from resting between loadings (Sharma and Yortsos, 1987). Hence, the removal of TS is governed by the resting period and flow velocity.

Table 3 Summary of overall treatment performance for each experimental runs.

HLR Influent (Inf.) and effluent (Eff.) contaminants mass (g), and removal efficiencies (RE)

(L) $\quad(\%)$

\begin{tabular}{llll|lll|lll|lll} 
& \multicolumn{1}{l}{ COD } & \multicolumn{1}{c}{ TS } & \multicolumn{3}{c}{ NH $_{4^{+}-\mathbf{N}}$} & \multicolumn{3}{c}{ TN } \\
\cline { 2 - 13 } & Inf. & Eff. & RE & Inf. & Eff. & RE & Inf. & Eff. & RE & Inf. & Eff. & RE \\
\hline 75 & 76.0 & 6.0 & 92.1 & 247.8 & 75.4 & 69.6 & 2.6 & 0.4 & 84.6 & 6.5 & 1.2 & 81.5 \\
& 85.2 & 5.5 & 93.5 & 86.1 & 10.8 & 87.5 & 1.9 & 0.4 & 78.9 & 2.4 & 0.7 & 70.8 \\
& 65.6 & 5.5 & 91.8 & 90.2 & 51.5 & 42.9 & 2.9 & 0.4 & 86.2 & 5.2 & 0.8 & 84.6 \\
& 56.0 & 4.2 & 92.5 & 78.6 & 11.2 & 85.7 & 2.0 & 0.6 & 70.0 & 4.4 & 1.1 & 75.0 \\
\hline \multirow{2}{*}{100} & 528.0 & 15.5 & 97.1 & 902.8 & 197.5 & 78.1 & 4.4 & 1.5 & 65.9 & 17.1 & 2.0 & 88.3 \\
& 417.1 & 21.7 & 94.8 & 610.7 & 96.9 & 84.1 & 4.1 & 1.0 & 75.6 & 9.8 & 2.0 & 79.6 \\
& 294.6 & 11.9 & 96.0 & 322.5 & 28.0 & 91.3 & 3.4 & 1.0 & 70.6 & 10.5 & 5.1 & 51.4 \\
& 117.4 & 1.9 & 98.4 & 243.4 & 41.0 & 83.2 & 3.7 & 0.2 & 94.6 & 5.0 & 0.8 & 84.0 \\
\hline \multirow{2}{*}{125} & 54.6 & 0.5 & 99.1 & 130.6 & 36.5 & 72.1 & 0.9 & 0.03 & 96.7 & 4.5 & 0.9 & 80.0 \\
& 29.5 & 0.3 & 99.0 & 67.0 & 6.8 & 89.9 & 0.3 & 0.01 & 96.7 & 2.0 & 0.1 & 95.0 \\
& 118.1 & 0.7 & 99.4 & 173.4 & 3.7 & 97.9 & 1.1 & 0.04 & 96.4 & 2.8 & 0.6 & 78.6 \\
& 33.7 & 0.5 & 98.5 & 52.5 & 15 & 71.4 & 0.9 & 0.02 & 97.8 & 1.6 & 0.2 & 87.5 \\
\hline
\end{tabular}

254

Moreover, no significant differences were observed for the removal of $\mathrm{NH}_{4}{ }^{+}-\mathrm{N}$ between low and moderate HLR cases. The average removal efficiencies for low and moderate HLR cases were approximately $80 \%$. However, high HLR cases was observed to have average removal efficiencies of 97\%. The sludge deposit layer may favour $\mathrm{NH}_{4}{ }^{+} \mathrm{N}$ adsorption and subsequently, nitrifying ammonium during resting (Molle, 2014). A thicker sludge deposit layer, as that of high HLR cases indicates that the adsorption site for $\mathrm{NH}_{4}{ }^{+}-\mathrm{N}$ is larger as compared to those of low and moderate HLR cases. Nevertheless, a more complete nitrification of $\mathrm{NH}_{4}+-\mathrm{N}$ would have occurred due to the reduced flow rate for high HLR cases as compared to that of low and moderate HLR cases (Sirianuntapiboon et al., 2006). Likewise, low and moderate HLR cases show no significant differences for the removal of TN with average removal efficiencies of approximately 77\%, high HLR cases showed better efficiency in TN removal with efficiencies of approximately $85 \%$. Although removal of TN was highly dependent on denitrification process in constructed wetlands (Saeed and Sun, 2012), denitrification in VFCW is assumed to be insignificant due to the system's ability to provide high levels of oxygen. Also, TN in septage is the sum of organic nitrogen and $\mathrm{NH}_{4}{ }^{+} \mathrm{N}$ (USEPA, 1999). Therefore, the 
concentrations of TN would be highly affected by the removal of $\mathrm{NH}_{4}{ }^{+}-\mathrm{N}$. Hence, the decrease in TN concentration over time was likely to be influenced by nitrification of ammonium, whereby the removal is further enhanced with increasing HRT. Furthermore, the TN removal rate is comparable to those in literature with removal efficiencies exceeding $80 \%$ (T. Koottatep et al., 2001; Paing and 273 Voisin, 2005).

\subsection{Retention Time Distribution (RTD) Analysis}

In addition to the established influent-effluent monitoring method, a better description of the treatment performance of the VFCW can be obtained by studying the correlation between its treatment performances with the hydraulic behaviour of the water in the system. This provides a better insight to the mass loss of pollutant in the system. The relationship between the mass loss of pollutant in the system is correlated to the HRT by RTD curves of pollutant concentration, where the RTD curves represent the time which various portion of fluid spends in the system. Previous studies have shown that increasing HRT would result in better treatment performance (Cota et al., 2011; Jong and Tang, 2016; Molle et al., 2006)

Figure 3 below shows the RTD curve plots for low, moderate, and high HLR cases. The RTD curves were observed to conform to the effluent flux profiles (as shown in Figure 2) for unsaturated conditions. This was expected as the tracer concentration was injected using a step input method. As the tracer is conservative in nature, its mass would be consistent, thus, the RTD curves produced would be expected to have a similar profile to that of effluent flux curves for individual HLR runs. The obtained RTD curves confirms the assumption that tracer is homogenised in the liquid, and follows the same flow pattern, giving it a reasonable reflection of the hydraulic RTD (Headley and Kadlec, 2007).

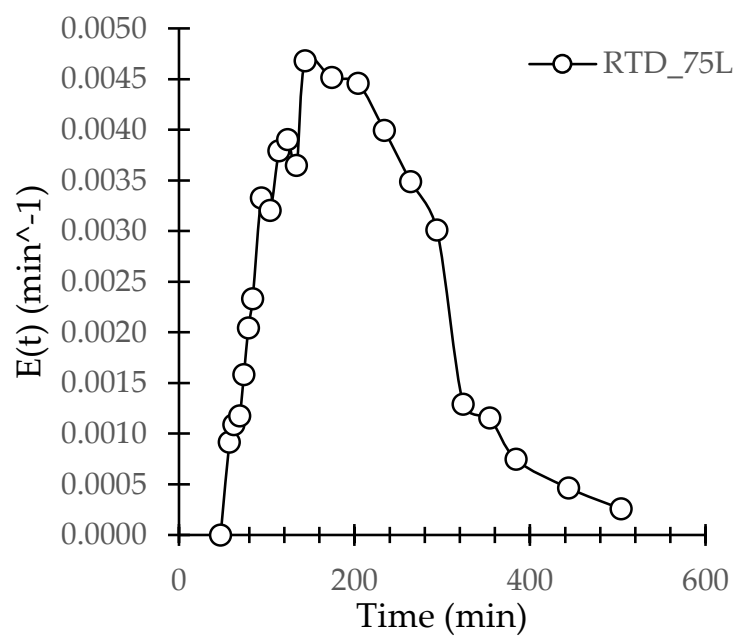

(a)

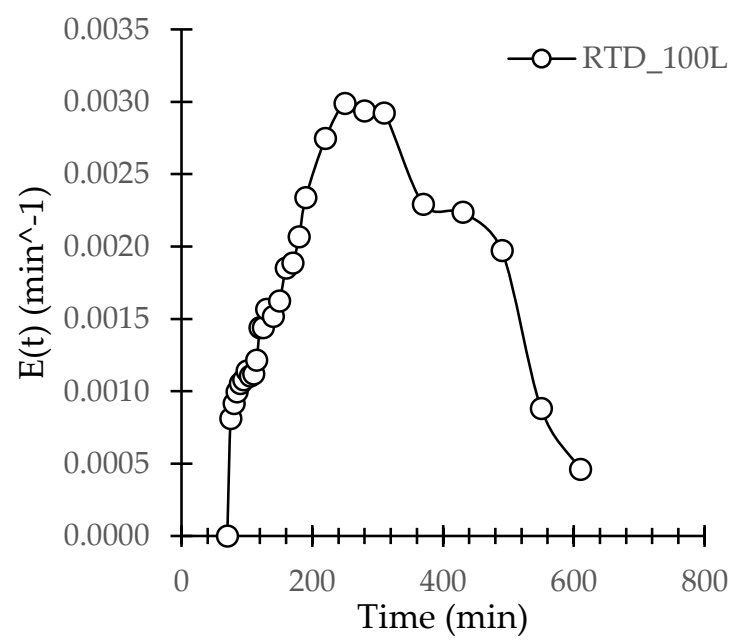

(b) 


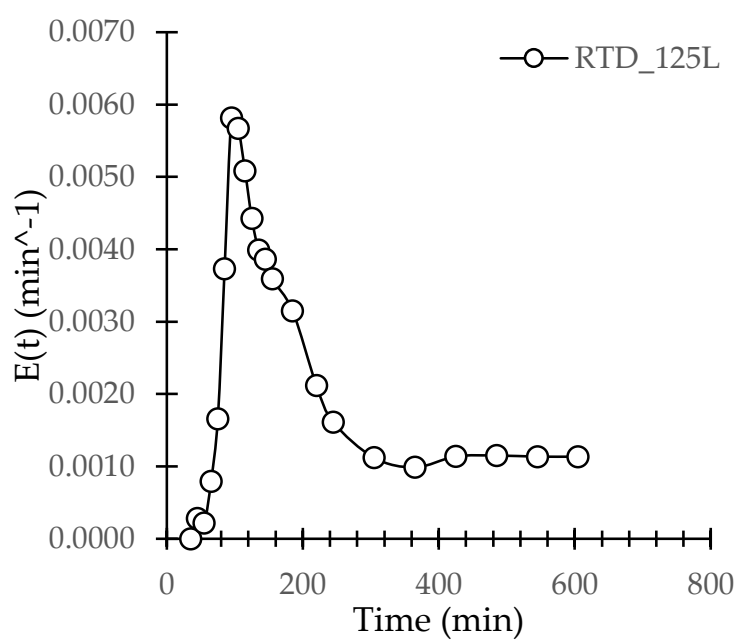

(c)

Figure 3 Representative RTD curves presented for varying HLR cases: (a) low HLR; (b) moderate HLR; (c) high HLR. The RTD curves observed conforms to that of the effluent flow profile of all HLR cases.

Still, the RTD curves observed do not show a typical bell shaped curve as those found in literature (Kadlec and Wallace, 2008; Giraldi et al., 2009). Instead, the asymmetry and long tail observed is similar to those found in (Cota et al., 2011). Hence, it is in all likelihood that the asymmetry and long tail observed in the RTD curves is due to diffusion of water into dead zones in the system, which is gradually released over time. Also, the long tail may be related to the adsorption of tracer in the biomass (Levenspiel, 2000).

Further analysis shows that the average HRT for low, moderate, and high HLR cases are 183 minutes, 263 minutes, and 288 minutes respectively. The increase of HRT may be related to the increase in solids content and sludge deposit layer thickness, which would have reduced the flow rate of effluent due to reduced effective porosity and capillary effect respectively (Molle, 2014). Moreover, the effect of increased HRT for high HLR cases was observed with the increase in COD, $\mathrm{NH}_{4}{ }^{+}-\mathrm{N}$ and $\mathrm{TN}$ removal.

Additionally, the degree of mixing (i.e. variance), which characterises a distribution of residence times in the wetland (i.e. the parcel of water travelling through the substrate media of the wetland reaches the output at different times) (Headley and Kadlec, 2007), increased as HLR increased. The average variances of the low, moderate, and high HLR cases were $7047 \mathrm{~min}^{2}, 9062 \mathrm{~min}^{2}$, and 17577 $\min ^{2}$ respectively. Similar observations were reported in (Giraldi et al., 2009), which stated that the degree of mixing in the system is controlled by HLR intensities, in which higher HLR would ultimately result in a more thorough mixing of fluid in the VFCW system. Therefore, resulting in greater treatment performance.

A correlation between treatment dynamics and hydraulic behaviour can be observed by plotting RTD curves with the concentration of pollutants. Figure 4 below shows the concentration of pollutants, namely nitrogen compound, COD, and TS, plotted against RTD curves. 


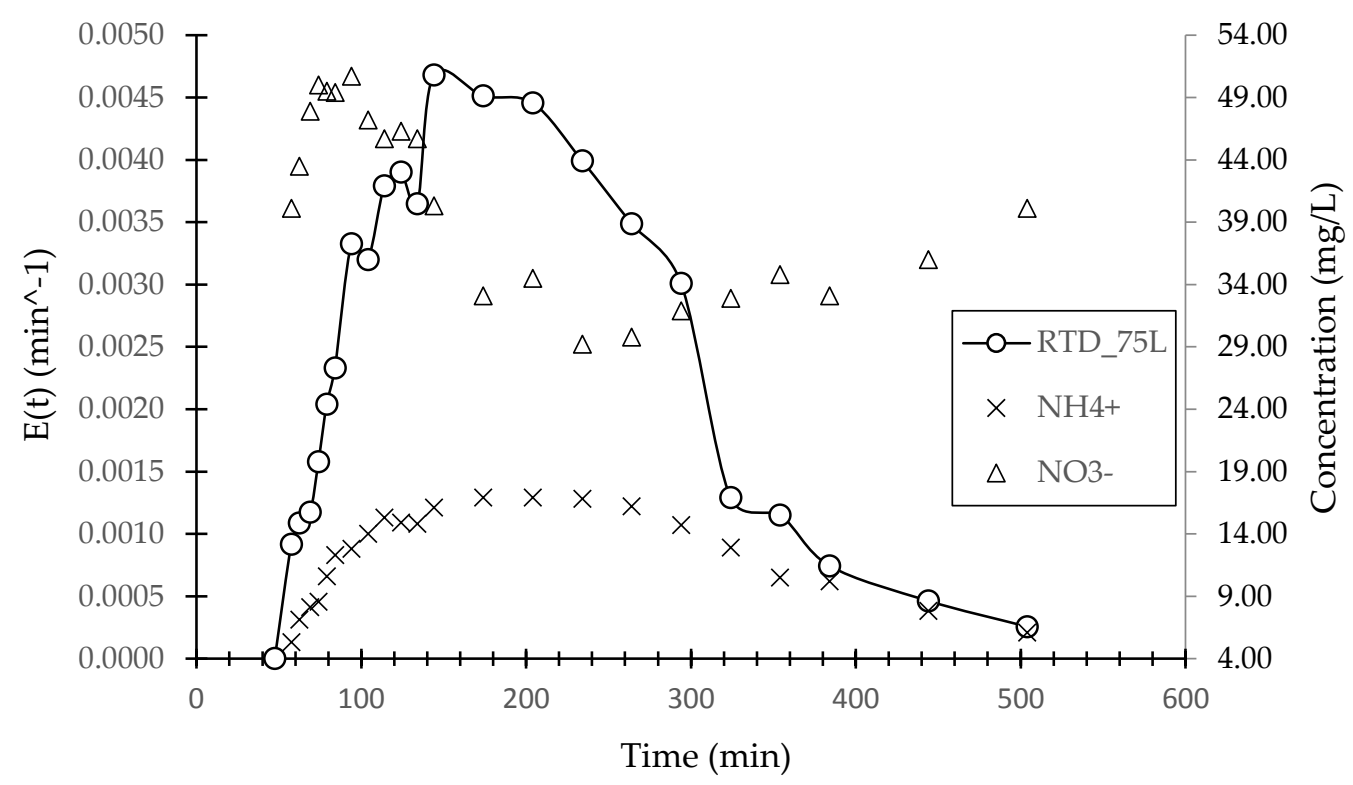

(a)

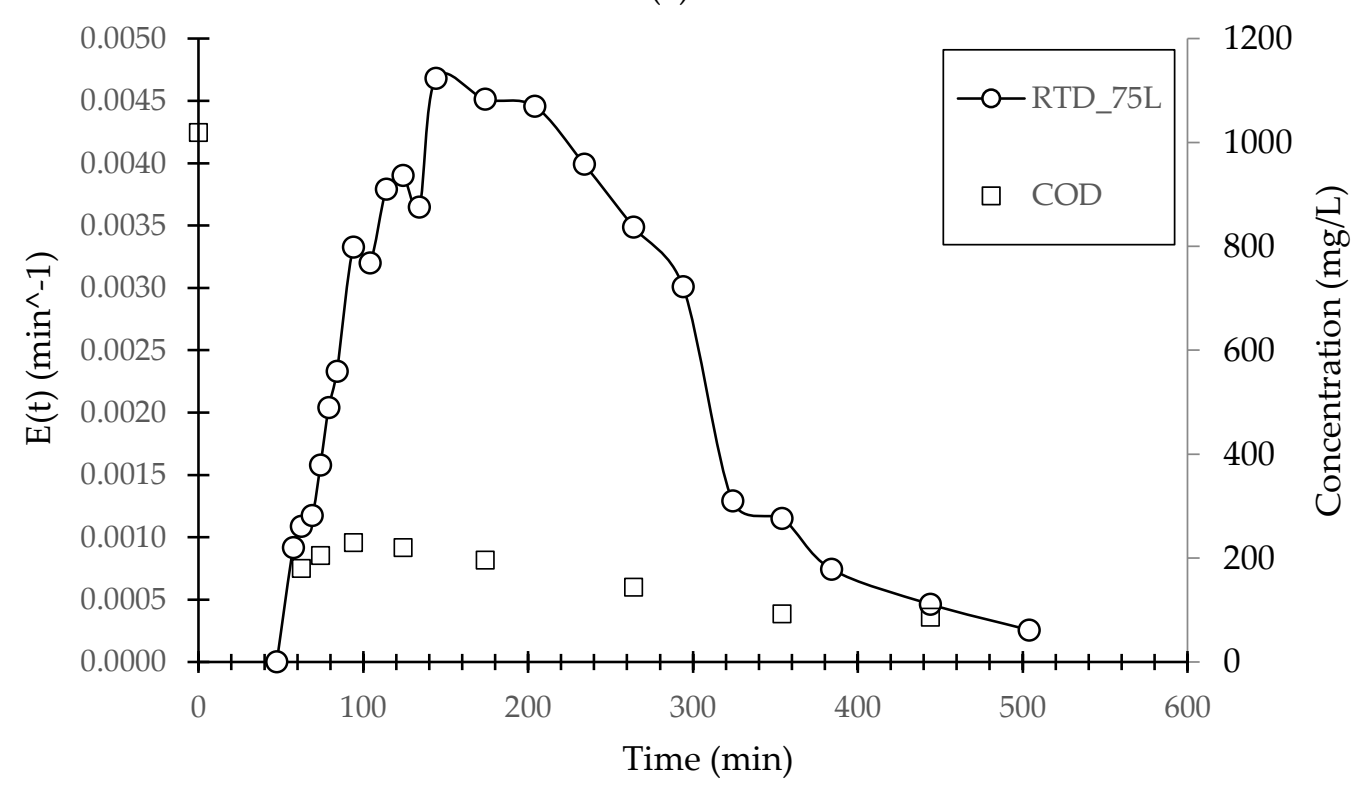

(b)

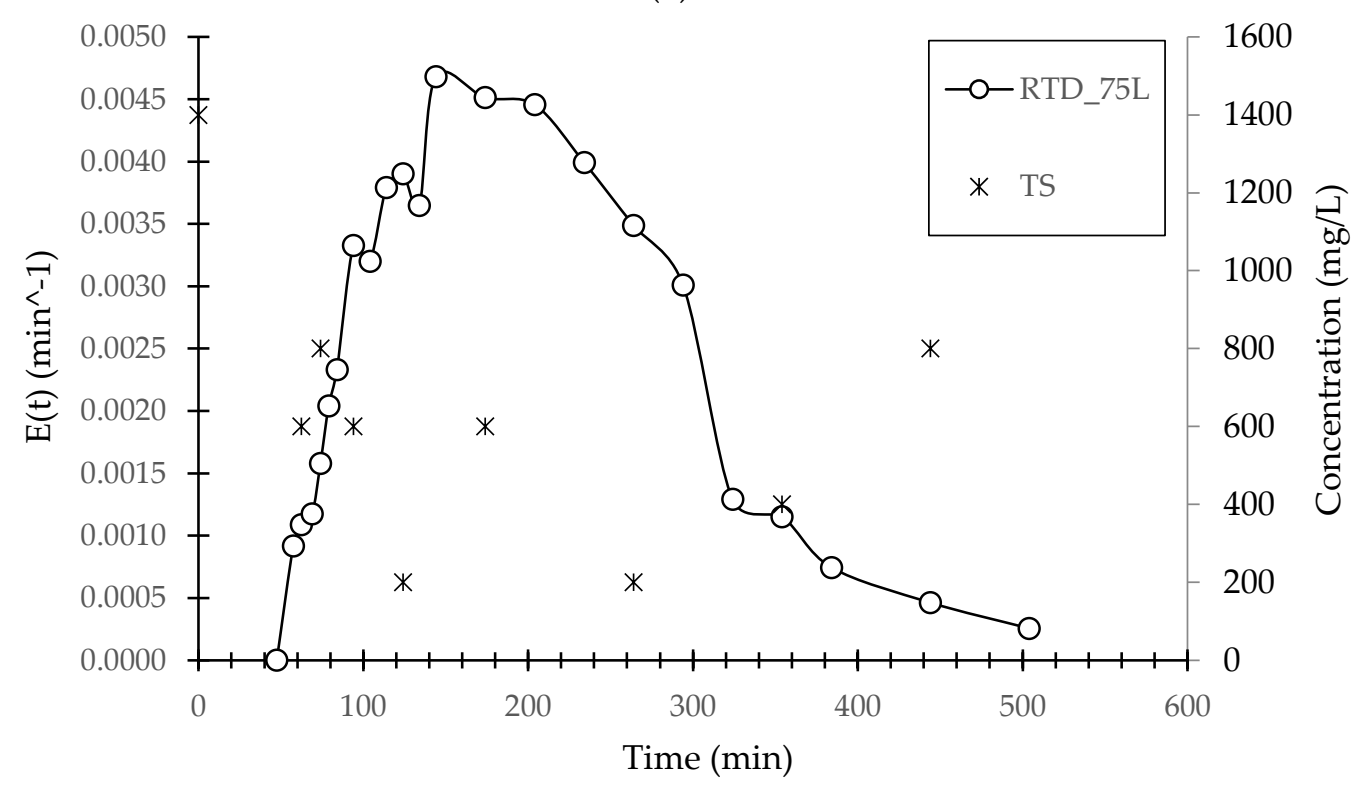


Figure 4 Representative RTD curves due to Low HLR cases with pollutant concentrations: (a) Nitrogen compound; (b) COD; (c) TS. The RTD shows a relationship with nitrogen compound and COD, but no relationship was observed with TS.

Figure 4(a) indicates that the amount of time effluent spends in the system highly affects $\mathrm{NH}_{4}{ }^{+}-$ $\mathrm{N}$ and $\mathrm{NO}_{3}{ }^{-} \mathrm{N}$ removal. The $\mathrm{NH}_{4}{ }^{+}-\mathrm{N}$ concentration decreases as the time spent by the effluent in the wetland system increases. However, it is interesting to note that at the initial stages of flow, the concentration of $\mathrm{NH}_{4}{ }^{+}-\mathrm{N}$ increases significantly with HRT before stabilizing and decreasing again. This could result from the flushing out of adsorbed $\mathrm{NH}_{4}{ }^{+}-\mathrm{N}$ in the biofilms. The lower concentrations of $\mathrm{NH}_{4}{ }^{+}-\mathrm{N}$ indicated that most of the adsorbed $\mathrm{NH}_{4}{ }^{+}-\mathrm{N}$ underwent nitrification during the resting period. Likewise, the increase in $\mathrm{NO}_{3}-\mathrm{N}$ concentration conforms that most of the adsorbed $\mathrm{NH}_{4}{ }^{+}-\mathrm{N}$ underwent nitrification. At the initial stages of flow, $\mathrm{NO}_{3}-\mathrm{N}$ concentration increases significantly which suggest that $\mathrm{NO}_{3}-\mathrm{N}$ is flushed out. Over time, the concentration of $\mathrm{NO}_{3}-\mathrm{N}$ decreases before increasing again with increasing HRT. The decrease would suggest that the flushing rate of nitrified $\mathrm{NH}_{4}{ }^{+}-\mathrm{N}$ adsorbed in the biofilm is greater than the rate of adsorption. Thus, the results are consistent with literature, which states that increasing HRT would increase nitrogen removal (Sirianuntapiboon et al., 2006).

The effect of HRT is also prominent in the removal of organic matter as seen in Figure 4(b). The concentration of COD showed significant reduction from its initial values, followed by a gradual decrease in concentrations with increasing HRT. The significant drop in concentration may imply enhanced filtration from the sludge deposit layer (Molle, 2014). Moreover, improvement in filtration efficiency may also result from a thicker sludge deposit layer as observed from the higher removal efficiency in high HLR cases. Subsequently the increased contact time between contaminants and the substrate would improve aerobic degradation (Saeed and Sun, 2012), resulting in the gradual decrease in concentration with increasing HRT.

Finally, no correlation between TS removal and HRT was observed. This is indicated by the degree of fluctuation in TS concentration with increasing HRT. However, as previously discussed, the removal of TS may be related to the resting period and flow velocity.

\section{Conclusions}

This study examined the effect of HLR on the hydraulic behaviour of VFCWs designed for septage treatment, and its correlation with the treatment dynamics. RTD analysis was conducted to understand the hydraulic characteristics of the system by means of analysing the average HRT as well as the treatment dynamics due to varying HLR intensity.

Effluent flow patterns for each loading resulted in a predictable trend, categorized by three stages of flow. The outflow velocity observed in all experimental runs suggest that solids content and thickness of sludge deposit layer was the controlling factor, with reduced outflow velocity as solids content and thickness of sludge deposit layer increases. Water recovery varied significantly for all HLR cases. A reduction in average recovery was observed with increasing HLR. The system's ability to recover water was observed to be related to the solids content and sludge deposit layer.

Overall removal of organic matter and nitrogen compound improved with increased HRT. However, no correlation between HRT and total solids removal was observed. The effects of HRT on treatment dynamics was further analysed by plotting RTD curves with pollutant concentrations. It was determined that the sludge deposit layer may have played a vital role in the removal of organic matter, nitrogen compounds and total solids. However, total solids removal was highly dynamic and easily influenced by resting periods between loadings and flow velocity.

It is expected that this study would contribute to a better understanding of the hydraulic behaviour and the treatment dynamics for a VFCW system designed for septage treatment as well as to support the modelling and calculation of pollutant removals. Further emphasis should be made to understand the role of sludge deposit layer in terms of hydraulics and treatment efficiency. 
376 Acknowledgments: The authors would like to acknowledge the Faculty of Engineering and Science, and Curtin 377 University Malaysia for supporting this study.

378 Author Contributions: All authors contributed equally to this work.

379 Conflicts of Interest: The authors declare no conflict of interest. 


\section{References}

Bradley, R. M. and Dhanagunan, G. R. (2004), 'Sewage sludge management in Malaysia', International Journal of Water, 2(4), 267-283.

Cofie, O. O., Agbottah, S., Strauss, M., Esseku, H., Montangero, A., Awuah, E. and Kone, D. (2006), 'Solid-liquid separation of faecal sludge using drying beds in Ghana: Implications for nutrient recycling in urban agriculture', Water Research, 40(1), 75-82.

Cota, R. S., von Sperling, M. and Penido, R. C. S. (2011), 'Tracer studies and hydraulic behaviour of planted and un-planted vertical-flow constructed wetlands', Water Science and Technology, 64(5), 1056-1063.

Fogler, H. S. and Brown, L. (1986), 'Distributions of residence times for chemical reactors', Elements of chemical reaction engineering, 708-758.

Ghosh, D. and Gopal, B. (2010), 'Effect of hydraulic retention time on the treatment of secondary effluent in a subsurface flow constructed wetland', Ecological Engineering, 36(8), 1044-1051.

Giraldi, D., de'Michieli Vitturi, M., Zaramella, M., Marion, A. and Iannelli, R. (2009), 'Hydrodynamics of vertical subsurface flow constructed wetlands: Tracer tests with rhodamine WT and numerical modelling', Ecological Engineering, 35(2), 265-273.

Headley, T. R. and Kadlec, R. H. (2007), 'Conducting hydraulic tracer studies of constructed wetlands: a practical guide', Ecohydrology \& Hydrobiology, 7(3), 269-282.

Hua, G., Zeng, Y., Zhao, Z., Cheng, K. and Chen, G. (2014), 'Applying a resting operation to alleviate bioclogging in vertical flow constructed wetlands: An experimental lab evaluation', Journal of Environmental Management, 136(Supplement C), 47-53.

Jong, V. S. W. and Tang, F. E. (2016), 'Contaminant removal in septage treatment with vertical flow constructed wetlands operated under batch flow conditions', Water Science and Technology, 73(4), 909-915.

Kadlec, R. H. and Wallace, S. (2008) Treatment wetlands, CRC press.

Koottatep, T., Polprasert, C., Oanh, N. T. K., Heinss, U., Montangero, A. and Strauss, M. (2001), 'Septage dewatering in vertical-flow constructed wetlands located in the tropics', Water Science and Technology, 44(2-3), 181-188.

Koottatep, T., Polpraserta, C., Oanha, N., Heinssb, U., Montangerob, A. and Straussb, M. (2001), 'Potentials of vertical-flow constructed wetlands for septage treatment in tropical regions', Advances in Water and Wastewater Treatment Technology: Molecular Technology, Nutrient Removal, Sludge Reduction, and Environmental Health, 315. 
Koottatep, T., Surinkul, N., Polprasert, C., Kamal, A. S. M., Koné, D., Montangero, A., Heinss, U. and Strauss, M. (2005), 'Treatment of septage in constructed wetlands in tropical climate: lessons learnt from seven years of operation', Water Science and Technology, 51(9), 119-126.

Kumar, J. L. G. and Zhao, Y. Q. (2011), 'A review on numerous modeling approaches for effective, economical and ecological treatment wetlands', Journal of Environmental Management, 92(3), 400-406.

Lana, L. C. O., Moraes, D. C., von Sperling, M., Morato, M. L. N., Vasconcellos, G. R., Paraense, M. O. and Moreira, T. P. A. (2013), 'Performance of a single stage vertical flow constructed wetland system treating raw domestic sewage in Brazil', Water Science and Technology, 68(7), 1599-1606.

Langergraber, G. (2005), 'The role of plant uptake on the removal of organic matter and nutrients in subsurface flow constructed wetlands: a simulation study', Water Science and Technology, 51(9), 213-223.

Langergraber, G., Haberl, R., Laber, J. and Pressl, A. (2003), 'Evaluation of substrate clogging processes in vertical flow constructed wetlands', Water Science and Technology, 48(5), 25-34.

Levenspiel, O. (2000). Chemical Reaction Engineering. $3^{\text {rd }}$ ed. New Jersey: United States, p.688. ISBN: 047125424X.

Liu, L., Zhao, X., Zhao, N., Shen, Z., Wang, M., Guo, Y. and Xu, Y. (2013), 'Effect of aeration modes and influent $\mathrm{COD} / \mathrm{N}$ ratios on the nitrogen removal performance of vertical flow constructed wetland', Ecological Engineering, 57(Supplement C), 10-16.

Molle, P. (2014), 'French vertical flow constructed wetlands: a need of a better understanding of the role of the deposit layer', Water Science and Technology, 69(1), 106-112.

Molle, P., Liénard, A., Grasmick, A. and Iwema, A. (2006), 'Effect of reeds and feeding operations on hydraulic behaviour of vertical flow constructed wetlands under hydraulic overloads', Water Research, 40(3), 606612.

Paing, J. and Voisin, J. (2005), 'Vertical flow constructed wetlands for municipal wastewater and septage treatment in French rural area', Water Science and Technology, 51(9), 145-155.

Rajabzadeh, A. R., Legge, R. L. and Weber, K. P. (2015), 'Multiphysics modelling of flow dynamics, biofilm development and wastewater treatment in a subsurface vertical flow constructed wetland mesocosm', Ecological Engineering, 74(Supplement C), 107-116.

Saeed, T. and Sun, G. (2012), 'A review on nitrogen and organics removal mechanisms in subsurface flow constructed wetlands: Dependency on environmental parameters, operating conditions and supporting media', Journal of Environmental Management, 112(Supplement C), 429-448.

Sharma, M. M. and Yortsos, Y. C. (1987), 'Transport of particulate suspensions in porous media: Model formulation', AIChE Journal, 33(10), 1636-1643. 
Sirianuntapiboon, S., Kongchum, M. and Jitmaikasem, W. (2006), 'Effects of hydraulic retention time and media of constructed wetland for treatment of domestic wastewater', African Journal of Agricultural Research, $1(2), 027-037$.

Tanner, C. C., Clayton, J. S. and Upsdell, M. P. (1995), 'Effect of loading rate and planting on treatment of dairy farm wastewaters in constructed wetlands $-\mathrm{I}$. Removal of oxygen demand, suspended solids and faecal coliforms', Water Research, 29(1), 17-26.

United States Environmental Protection Agency (USEPA) (1999), Decentralized Systems Technology Fact Sheet, Septage Treatment/Disposal. Washington, DC, USA: USEPA.

Vrhovšek, D., Kukanja, V. and Bulc, T. (1996), 'Constructed wetland (CW) for industrial waste water treatment', Water Research, 30(10), 2287-2292. of constructed wetlands', Constructed wetlands for wastewater treatment in Europe, 17-66. 